\title{
Predictors of repeated sick leave in the workplace because of mental disorders
}

\author{
This article was published in the following Dove Press journal: \\ Neuropsychiatric Disease and Treatment \\ 29 January 2014 \\ Number of times this article has been viewed
}

\author{
Mitsuhiro Sado' \\ Joichiro Shirahase' \\ Kimio Yoshimura ${ }^{2}$ \\ Yuki Miura' \\ Kazuhiro Yamamoto' \\ Hajime Tabuchi' \\ Motoichiro Kato' \\ Masaru Mimura' \\ 'Department of Neuropsychiatry, \\ Keio University School of \\ Medicine, Shinjuku-ku, Tokyo, Japan; \\ 2Department of Health Policy and \\ Management, Keio University School \\ of Medicine, Shinjuku-ku, Tokyo, Japan
}

Correspondence: Mitsuhiro Sado

Department of Neuropsychiatry,

Keio University School of Medicine,

Shinanomachi 35, Shinjuku-ku,

Tokyo 160-8582, Japan

Tel $+8 \mid 33353$ I2II ext 62454

Fax +81353790187

Email mitsusado@z5.keio.jp
Introduction: Mental disorders create a considerable burden to society. Previous studies have shown that productivity loss constitutes the largest proportion of the total societal burden. For depression and anxiety disorders, in particular, more than half of the associated productivity loss occurs in the workplace. Many previous studies have clarified the risk factors for the relapse/ recurrence of mental disorders in health care settings. However, the risk factors for repeated sick leave among mental disorders prevalent in the workplace have not yet been adequately evaluated.

Objective: The objective of this study was to investigate which variables could predict repeated sick leave for workers with a history of sick leave because of mental disorders.

Methods: Data regarding 194 subjects employed at a manufacturing company were obtained. Mental disorders were defined as disorders listed in the Diagnostic and Statistical Manual of Mental Disorders, fourth edition (DSM-IV). The duration between the return to work (RTW) and the repeated sick leave was regarded as a dependent variable. The subjects' age at the RTW, sex, age at the time of employment, job tenure, diagnosis, number of previous sick leave days, duration of most recent sick leave, and employee rank were examined as explanatory variables. Univariate analyses using a log-rank test and a multivariate analysis using the Cox proportional hazard model were conducted.

Results: The results of the univariate analyses showed that the number of previous sick-leave episodes was a significant predictor of repeated sick leave. A multivariate analysis revealed that age at RTW and the number of previous sick-leave episodes were significant variables.

Conclusion: Age and the number of previous sick-leave episodes appeared to be predictors of repeated sick leave. Therefore, effective intervention to prevent repeated sick leave for those with high risk is quite crucial. Analyses including various work-related factors with subjects from multiple companies should be conducted in future studies.

Keywords: sickness absence, occupational mental health, relapse/recurrence

\section{Introduction}

Mental disorders create a considerable burden to society. The Global Burden of Disease study ${ }^{1}$ reported that mental and behavioral disorders constitute $7.4 \%$ of the societal burden incurred by all diseases. In many developed countries, productivity loss because of mental disorders has become a considerable issue. ${ }^{2-6}$ In the UK, mental disorders are reportedly the cause of $40 \%$ of all sick leave. ${ }^{7}$ In Japan as well, the costs of productivity loss attributable to mental disorders are enormous. Productivity loss (ie, absenteeism/ presenteeism, unemployment costs, and mortality cost) associated with schizophrenia, depression, and anxiety disorders has been estimated at JPY 2.0 trillion (USD 17 billion), JPY 2.9 trillion (USD 25 billion), and JPY 2.3 trillion (USD 20 billion), 
respectively (Purchasing Power Parity between JPY and USD in 2008 [USD $1=$ JPY 116.8] was used to calculate the USD equivalent of each cost component). ${ }^{8,9}$ For depression and anxiety disorders in particular, more than half of the loss was a result of absenteeism/presenteeism. ${ }^{8,9}$ Therefore, improving productivity loss in the workplace is one of the most significant elements for mitigating the societal burden of mental disorders. Considering the fact that mental disorders are likely to relapse or recur easily, ${ }^{10,11}$ preventing relapses or recurrences of mental disorders is important.

The risk factors for the relapse/recurrence of depression have been evaluated in various studies, ${ }^{12-20}$ with factors such as a history of previous episodes, residual symptoms, and decreased psychosocial functioning reportedly increasing the risk of relapse/recurrence. However, these studies were performed in health care settings only. When considering productivity loss, the focus of attention should be the workplace, where repeated sick leave (rather than relapse/recurrence) should be considered as the most significant outcome, as it directly leads to productivity loss. In the workplace, sick leave because of mental disorders is not restricted to depression, but includes a variety of disorders, such as adjustment disorder, anxiety disorder, bipolar disorder, schizophrenia, for example. Therefore, investigating the risk factors for repeated sick leave among mental disorders prevalent in the workplace is crucial when considering the impact of mental disorders on productivity loss. However, only a few studies have evaluated the risk factors of repeated sick leave in the workplace to date. A study conducted by Koopmans ${ }^{21}$ in the Netherlands is one of the few studies related to this field. Koopsman reported that persistent depressive symptoms in men arising from common mental disorders (CMDs), men between the ages of 45 and 55 years, women under 45 years of age, lower salary, married women, and women with a duration of employment shorter than 5 years were risk factors of repeated sick leave.

On the other hand, whether these findings are applicable to countries other than the Netherlands is uncertain because of differences in background factors, such as health care systems and employment contracts regarding sick leave, among different countries. These possible predictors of repeated sick leave have not been previously investigated in Japan. Therefore, we decided to evaluate predictors of repeated sick leave in a Japanese work setting. In addition, although clinical and demographic factors have been previously evaluated, work roles were not included in this analysis. ${ }^{21}$ Therefore, we decided to include work-related factors as variables in the analyses.

\section{Objective}

The objective of this study was to evaluate which variables are capable of predicting the risk of repeated sick leave among workers with a history of sick leave because of a mental disorder.

\section{Methods Design}

This was a retrospective cohort study.

\section{Subjects}

Data were obtained from a manufacturing company in Japan, where approximately 10,000 people were employed in the Tokyo metropolitan area, and $81 \%$ of them were male. Data from employees were included in the analyses if they had returned to work between April 1, 2009, and March 31, 2012, after taking sick leave that had lasted longer than 20 days and that had been necessitated by a mental disorder. A cutoff point of 20 days was adopted, because according to the company's regulations, employees who require sick leave lasting longer than 20 days must undergo an assessment by an occupational psychiatrist to determine whether they are mentally fit to return to work. Mental disorders were defined as the disorders listed in the Diagnostic and Statistical Manual of Mental Disorders, fourth edition (DSM-IV). Participants who took sick leave because of both physical and mental disorders were included in the analyses only when the main reason for the sick leave was judged by an occupational psychiatrist to be a mental disorder.

Clinical diagnoses coded according to the DSM-IV criteria were made clinically without any structured clinical interview by a senior psychiatrist, who had reviewed information from psychotherapists and interviews with the subjects, their coworkers, and personnel in the company's human resource division. The diagnosis affecting the most recent sick leave was recorded as the primary diagnosis and was used for the analyses.

\section{Process for returning to work}

Once the subjects submitted a medical certificate to the human resource division for returning to work, they were referred to the occupational mental health support team. The employees participated in a brief rehabilitation program provided by psychotherapists that contained components of cognitive behavior therapy, such as behavior activation, activity records, and case formulation. Typically, after completing four sessions of the abovementioned interventions, 
the employees were evaluated by a psychiatrist to determine whether they were fit to return to work. If the subject was judged to be fit to return to work, they were allowed to do so with some restrictions on their activities. These restrictions were removed in a step-by-step manner until they had been completely removed after 6 months.

\section{Variables}

\section{Dependent variable}

The duration between the return to work (RTW) and the repeated sick leave was regarded as a dependent variable. RTW was defined as the start of full-time work after sick leave lasting longer than 20 days and necessitated by a mental disorder, while repeated sick leave was defined as the restart of sick leave lasting longer than 20 days and necessitated by a mental disorder.

\section{Explanatory variables}

Because RTW is a multifactorial outcome, ${ }^{22}$ obtaining a wide range of data for specific variables across various diagnostic, sociodemographic, work-related, and personality parameters is essential. On the other hand, for daily occupational mental health activities, obtaining extensive data, for example through structured interviews for all employees undergoing an RTW is unrealistic. Therefore, we instead focused on variables that could be reasonably obtained during typical RTW assistance so as to assess whether such "easy to obtain" variables can be used to predict repeated sick leave.

We divided the explanatory variables into three categories: sociodemographic, diagnostic, and work-related. Further details of each category are given below.

\section{Sociodemographic factors}

Age at RTW, sex, age at employment of this company, and job tenure were examined as explanatory variables.

\section{Diagnostic factors}

Diagnosis, the number of previous sick-leave episodes, and the duration of the latest sick leave were examined.

\section{Work-related factors}

Employee rank at RTW was defined as being a work-related factor. Employee rank fell into four categories as follows: assistant staff, normal staff, senior staff, and manager. Employee ranks were strongly correlated to the job role at the company. Typical job roles for each employee rank are described below.

\section{Assistant staff}

The expected job roles of assistant staff were to support and help other employees work efficiently by collecting data or making presentation slides, for example.

\section{Normal staff}

The job roles of normal staff are to conduct tasks assigned by the senior staff. Although these employees occasionally need to collaborate with colleagues, they mainly conduct tasks on an individual basis.

\section{Senior staff}

Senior staff are expected to act as team leaders; a team typically consists of a small number of normal staff members. A team leader's mission is to manage the team so as to complete the tasks assigned by a manager.

\section{Manager}

Managers operate projects by managing several teams. Their main roles are to provide team leaders with missions and to control the progress of projects.

\section{Analysis}

As previously mentioned, factors capable of predicting repeated sick leave were assessed by conducting a log-rank test and Cox proportional hazard analyses. The dependent variable (the number of days until the repeated sick leave) was censored when participants were still working as of March 31, 2012, or had retired, or were transferred outside of the Tokyo metropolitan branch facility.

First, univariate analyses were conducted. Each explanatory variable was assessed using a log-rank test. In order to conduct log-rank test, all variables were categorized as shown in Table 1. Next, all the explanatory variables were inputted into the model, and a multivariate analysis was performed using the Cox proportional hazard model with stepwise variable selection. The predictor variables sex and age at RTW were forced into the model, and all the other variables were selected using the stepwise method. In the process of multivariate analysis, variables such as sex, the number of previous sick-leave episodes, diagnosis, and employee rank were treated as categorical variables, while others were imputed as continuous variables.

With regard to the number of prior sick-leave episodes, because the results of prior study showed that there was huge discrepancy in survival rate between two and three episodes, we decided to divide this variable between them. In the multivariate analysis, the hazard ratios of explanatory variables were presented compared with the reference category, 
the ratio of which was 1 . A hazard ratio larger than 1 indicated that the risk of sick leave was larger than that of the reference category. These analyses were conducted using SPSS (SPSS Inc, Chicago, IL, USA) for Windows, version 17.

\section{Ethical considerations}

To conduct the analyses, we secondarily utilized data that had already been obtained through the normal RTW process. Thus, it was difficult to obtain informed consent retrospectively from the employees who had participated in the RTW process. Since only anonymous data were used, we judged it to be unnecessary to obtain informed consent from the employees. This study was approved by the Clinical Research Ethics Committee of Keio University School of Medicine.

\section{Results}

\section{Subject characteristics}

\section{Sociodemographic variables}

The total number of subjects included in the analysis was 194; of those, 159 subjects were male and 35 were female. The study subjects ranged in age from 24 to 59 years, with a mean age \pm standard deviation (SD) of $38.4 \pm 7.0$ years. The subjects were stratified according to age category. The 30-39-year age group was the largest, followed by the 40-49-year and the 20-29-year age groups.

\section{Diagnostic variables}

Overall, 100 subjects (51.5\%) were diagnosed as having major depressive disorders, 55 (28.4\%) were diagnosed as having adjustment disorders, $15(7.7 \%)$ were diagnosed as having bipolar disorders, 7 (3.3\%) were diagnosed as having anxiety disorders, and 4 (2.6\%) were diagnosed as having schizophrenia. Other diagnoses included personality disorders, substance related disorders, somatoform disorders, eating disorders, pervasive development disorders, attentiondeficit and disruptive behavior disorders, and unspecific mental disorders. Overall, 122 subjects $(62.6 \%)$ had experienced one previous sick-leave episode, $46(23.6 \%)$ had experienced two episodes, 14 (7.2\%) had experienced three episodes, six $(3.0 \%)$ had experienced four episodes, five $(2.6 \%)$ had experienced five episodes, and one $(0.5 \%)$ had experienced six episodes. The mean duration of the latest sick leave \pm SD was $352.6 \pm 354.3$ days, and 29 subjects (14.9\%) had suffered repeated sick leave after RTW during the observational period (April 1, 2009, to March 31, 2012). The detailed characteristics of the subjects are shown in Table 1.
Table I Characteristics of the subjects $(n=194)$

\begin{tabular}{|c|c|c|}
\hline Predictor & $\mathbf{n}$ & $\%$ \\
\hline \multicolumn{3}{|l|}{ Sociodemographic } \\
\hline \multicolumn{3}{|l|}{ Age at return to work (years) } \\
\hline $20-29$ & 20 & 10.3 \\
\hline $30-39$ & 90 & 46.4 \\
\hline $40-49$ & 72 & 37.1 \\
\hline$\geq 50$ & 12 & 6.2 \\
\hline \multicolumn{3}{|l|}{ Sex } \\
\hline Male & 159 & 82.0 \\
\hline Female & 35 & 18.0 \\
\hline \multicolumn{3}{|l|}{ Age at initial employment (years) } \\
\hline$<24$ & 88 & 45.4 \\
\hline $25-29$ & 80 & 41.2 \\
\hline $30-34$ & 18 & 9.3 \\
\hline $35-39$ & 6 & 3.1 \\
\hline $40-50$ & 2 & 1.0 \\
\hline \multicolumn{3}{|l|}{ Tenure (years) } \\
\hline$<5$ & 28 & 14.4 \\
\hline $5-9$ & 54 & 27.8 \\
\hline $10-19$ & 78 & 40.2 \\
\hline$\geq 20$ & 34 & 17.5 \\
\hline \multicolumn{3}{|l|}{ Diagnostic } \\
\hline \multicolumn{3}{|c|}{ Number of previous sick-leave episodes } \\
\hline$<3$ & 168 & 86.6 \\
\hline$\geq 3$ & 26 & 13.4 \\
\hline \multicolumn{3}{|l|}{ Diagnosis } \\
\hline Major depressive disorder & 100 & 51.5 \\
\hline Adjustment disorder & 55 & 28.4 \\
\hline Bipolar disorder & 15 & 7.7 \\
\hline Anxiety disorder & 7 & 3.6 \\
\hline Schizophrenia & 4 & 2.1 \\
\hline Others & 13 & 6.7 \\
\hline \multicolumn{3}{|l|}{ Duration of sick leave (days) } \\
\hline$<90$ & 43 & 22.2 \\
\hline $90-180$ & 49 & 25.3 \\
\hline $18 \mid-365$ & 37 & 19.1 \\
\hline$>365$ & 65 & 33.5 \\
\hline \multicolumn{3}{|l|}{ Work related } \\
\hline \multicolumn{3}{|l|}{ Employee rank } \\
\hline Manager & 33 & 17.0 \\
\hline Senior staff & 102 & 52.6 \\
\hline Normal staff & 55 & 28.4 \\
\hline Assistant staff & 4 & 2.1 \\
\hline
\end{tabular}

\section{Univariate analyses}

The results are shown in Table 2. Only the number of previous sick-leave episodes was significant $(P<0.001)$.

\section{Multivariate analyses}

The result of model $\chi^{2}$ test was significant $(P<0.001)$. Among the variables that were examined, the age at RTW and the number of previous sick-leave episodes appeared to be significant. Regarding the age at RTW, the hazard ratio (95\% CI) was 0.923 (0.866-0.984). 
Table 2 Predictors for repeated sick leave (univariate analysis)

\begin{tabular}{|c|c|c|c|c|c|c|c|}
\hline \multirow[t]{2}{*}{ Predictor } & \multirow{2}{*}{$\begin{array}{l}\text { Estimated } \\
\text { survival days }\end{array}$} & \multirow[t]{2}{*}{ SE } & \multicolumn{2}{|l|}{$95 \% \mathrm{Cl}$} & \multirow[t]{2}{*}{$\chi^{2}$} & \multirow{2}{*}{$\begin{array}{l}\text { Degrees of } \\
\text { freedom }\end{array}$} & \multirow[t]{2}{*}{$P$-value } \\
\hline & & & Lower & Upper & & & \\
\hline \multicolumn{8}{|l|}{ Sociodemographic } \\
\hline \multicolumn{8}{|l|}{ Age at return to work (years) } \\
\hline $20-29$ & 585.8 & 85.0 & 419.1 & 752.4 & 5.15 & 3 & 0.16 \\
\hline $30-39$ & 931.0 & 41.5 & 849.6 & 1012.4 & & & \\
\hline $40-49$ & 940.3 & 43.3 & 855.4 & 1025.2 & & & \\
\hline$\geq 50$ & 603.4 & 61.6 & 482.6 & 724.2 & & & \\
\hline \multicolumn{8}{|l|}{ Sex } \\
\hline Male & 910.3 & 33.4 & 844.9 & 975.7 & 0.65 & I & 0.42 \\
\hline Female & 958.7 & 57.1 & 846.9 & 1070.6 & & & \\
\hline \multicolumn{8}{|c|}{ Age at initial employment (years) } \\
\hline$<24$ & 899.0 & 44.0 & 812.8 & 985.3 & 2.87 & 4 & 0.58 \\
\hline $25-29$ & 889.6 & 48.7 & 794.1 & 985.1 & & & \\
\hline $30-34$ & 993.8 & 57.2 & 881.7 & 1105.9 & & & \\
\hline $35-39 *$ & - & - & - & - & & & \\
\hline $40-50 *$ & - & - & - & - & & & \\
\hline \multicolumn{8}{|l|}{ Tenure (years) } \\
\hline$<5$ & 845.5 & 82.3 & 684.1 & 1006.9 & 1.23 & 3 & 0.75 \\
\hline $5-9$ & 889.3 & 57.6 & 776.4 & 1002.3 & & & \\
\hline $10-19$ & 936.7 & 42.1 & 854.3 & 1019.2 & & & \\
\hline$\geq 20$ & 904.7 & 63.1 & 781.0 & 1028.4 & & & \\
\hline \multicolumn{8}{|l|}{ Diagnostic } \\
\hline \multicolumn{8}{|c|}{ Number of previous sick-leave episodes } \\
\hline$\leq 2$ & 964.3 & 28.0 & 909.4 & 1019.1 & 15.68 & I & $<0.001$ \\
\hline$\geq 3$ & 624.3 & 101.2 & 426.0 & 822.7 & & & \\
\hline \multicolumn{8}{|l|}{ Diagnosis } \\
\hline Major depressive disorder & 855.4 & 41.3 & 774.4 & 936.4 & 7.93 & 5 & 0.16 \\
\hline Adjustment disorder & 972.2 & 46.9 & 880.2 & 1064.2 & & & \\
\hline Bipolar disorder & 774.5 & 92.3 & 593.7 & 955.3 & & & \\
\hline Anxiety disorder* & - & - & - & - & & & \\
\hline Schizophrenia & 238.9 & 60.3 & 120.6 & 357.1 & & & \\
\hline Others & 908.8 & 110.5 & 692.1 & 1125.4 & & & \\
\hline \multicolumn{8}{|l|}{ Duration of sick leave (days) } \\
\hline$<90$ & 991.1 & 49.2 & 894.7 & 1087.5 & 4.20 & 3 & 0.24 \\
\hline $90-180$ & 913.7 & 52.6 & 810.5 & 1016.8 & & & \\
\hline$|8|-365$ & 790.8 & 80.5 & 633.0 & 948.6 & & & \\
\hline$>365$ & 907.4 & 49.3 & 810.8 & 1004.0 & & & \\
\hline \multicolumn{8}{|l|}{ Work related } \\
\hline \multicolumn{8}{|l|}{ Employee rank } \\
\hline Manager & 882.6 & 64.3 & 756.6 & 1008.6 & 5.96 & 3 & 0.11 \\
\hline Senior staff & 958.2 & 34.5 & 890.5 & 1025.9 & & & \\
\hline Normal staff & 815.8 & 65.8 & 686.7 & 944.8 & & & \\
\hline Assistant staff* & - & - & - & - & & & \\
\hline
\end{tabular}

Note: *Survival days were not estimated because no incidence occurred during the observational period.

Abbreviations: $\mathrm{Cl}$, confidence interval; SE, standard error.

On the other hand, with respect to the number of previous sick-leave episodes, when two or fewer previous episodes were used as the reference level, the estimated hazard ratio increased from 1.00 for the reference to 4.83 for those with three or more episodes. The $95 \%$ CI was $2.19-10.64$. Further details are shown in Table 3.

Log minus log graph was drawn in order to assess the adequacy of the Cox regression model with regard to the number of previous sick-leave episodes. Both curves
( $\geq 2$ and $\leq 3$ ) appeared to be parallel. Therefore, we judged that the adequacy of this model was maintained.

\section{Discussion}

\section{Summary}

As previously mentioned, because a large proportion of societal costs arising from mental disorders are likely to occur in the workplace, preventing repeated sick leave because of relapse/recurrence is a significant issue. As far as we know, 
Table 3 Predictors for repeated sick leave (multivariate analysis)

\begin{tabular}{|c|c|c|c|c|c|c|c|c|}
\hline \multirow[t]{2}{*}{ Predictor } & \multirow[t]{2}{*}{$\beta$} & \multirow[t]{2}{*}{ SE } & \multirow[t]{2}{*}{ Wald } & \multirow[t]{2}{*}{$d f$} & \multirow[t]{2}{*}{$P$} & \multirow[t]{2}{*}{ Hazard ratio } & \multicolumn{2}{|c|}{ Hazard ratio } \\
\hline & & & & & & & Lower & Upper \\
\hline \multicolumn{9}{|c|}{ Sociodemographic } \\
\hline Age* & -0.080 & 0.033 & 5.993 & 1 & 0.014 & 0.923 & 0.866 & 0.984 \\
\hline \multicolumn{9}{|l|}{ Sex* } \\
\hline Male & & & & & & 1.000 & Reference & \\
\hline Female & -0.534 & 0.565 & 0.895 & 1 & 0.344 & 0.586 & 0.194 & 1.773 \\
\hline \multicolumn{9}{|l|}{ Diagnostic } \\
\hline \multicolumn{9}{|c|}{ Number of previous sick-leave episodes** } \\
\hline$\leq 2$ & & & & & & 1.000 & Reference & \\
\hline$\geq 3$ & $1.58 \mathrm{I}$ & 0.414 & 14.585 & I & $<0.001$ & 4.861 & 2.159 & 10.943 \\
\hline
\end{tabular}

Notes: *Analyzed using the forced entry method; **analyzed using the forward selection method (likelihood ratio).

Abbreviations: SE, standard error; $d f$, degrees of freedom.

this is the first study to evaluate the risk factors for repeated sick leave, not only from a diagnostic and demographic perspective but also from the perspective of work roles in a Japanese setting.

\section{Diagnostic variables}

Similar to the results of a previous study evaluating risk factors for relapse/recurrence, ${ }^{23}$ the number of previous sick-leave episodes was a strong predictor of repeated sick leave.

The present results indicated that subjects with more than three previous episodes were almost five times more likely to require repeated sick leave than those with one or two previous episodes. This result is consistent with the findings of previous studies, ${ }^{24-27}$ which showed that a larger number of previous episodes were associated with a higher risk of relapse/recurrence. On the other hand, previous studies have also implied that subclinical residual symptoms are another strong predictor. ${ }^{17,18,28-30}$ However, this parameter was not evaluated in the present study, because the subjects had different disorders, and the severity of the symptoms was difficult to measure using a single scale.

\section{Sociodemographic variables}

In the present study, a younger age was also a risk factor for repeated sick leave. This result is largely in accordance with the results of previous studies, which indicate that repeated sick leave because of CMDs is more common among younger subjects in studies conducted in the Netherlands. ${ }^{21,31,32}$ One possible explanation for this phenomenon is that the onset of mental illness at a younger age suggests a higher biological vulnerability for relapse or the recurrence of mental disorders. Another explanation might be the possibility of a selection bias, known as the "healthy workers effect." ${ }^{33}$ Workers suffering from mental disorders often leave the workplace as their age increases.
Actually, the result of studies conducted under a health care setting suggests that the relationship between age and the recurrence of depression is questionable. Hardeveld ${ }^{23}$ showed that the number of studies suggesting a significant association between age and recurrence is actually quite small $(n=2)$, compared with those that do not show a significant relationship ( $\mathrm{n}=9$ ).

Regarding gender, no difference in the risk of repeated sick leave was seen between men and women in the present study. A previous study also reported the same result. ${ }^{21}$ Another previous study, which evaluated risk factors for the recurrence of major depression through a systematic review, also concluded that gender was not a risk factor for the recurrence of major depression. ${ }^{23}$ Our findings seem to agree with the results of these previous studies. Interestingly, women are known to have a higher risk of the onset of a first depressive episode $\mathrm{e}^{34,35}$ and to require sick leave because of a CMD. ${ }^{31,36}$ However, this gender difference disappeared when recurrence or repeated sick leave was considered. The reason for this distinction remains unclear and should be addressed in future studies.

\section{Work-related variables}

As far as the authors know, the relationship between the work role and repeated sick leave has not been adequately investigated. This is one of the unique points of the present study. Our results did not show any relationship between the work role and the risk of repeated sick leave. However, the study population included in the present analysis might have been too small to detect a significant difference. Therefore, caution is needed when interpreting the results.

In summary, taking into consideration the fact that those who are at younger age and have more than three previous sick-leave episodes are at high risk of repeated sick leave, effective intervention to prevent repeated sick leave for those with high risk is quite crucial. 


\section{Limitations}

This study had some limitations, even though it presents significant knowledge. First, the study population was derived from a single company. Therefore, whether the results of this research are applicable to other companies or industries in Japan is still unclear. Second, all the subjects received specialized care from psychiatrists and psychotherapists before RTW. This care was relatively intense, compared with the typical assistance provided to employees who are RTW at a Japanese company. Thus, this intensive care might have reduced some risk factors for repeated sick leave. Third, diagnoses of the participants were made clinically without structured clinical interview. Therefore, the validation of diagnoses contains uncertainty to some degree. Fourth, the sample was relatively small in size and was derived from a single company. This might have biased the results to some extent. Finally, only a few work-related factors were evaluated, and other factors such as the work environment or interpersonal factors should be examined. Accordingly, these limitations should be carefully considered when interpreting the results of the present study, and future research should address these issues.

\section{Conclusion}

The present study investigated the predictors of repeated sick leave necessitated by mental disorders across multiple domains. The results showed that diagnostic (number of previous sick-leave episodes) and demographic (age) variables were predictors of repeated sick leave. Therefore, effective intervention to prevent repeated sick leave for those with high risk is quite crucial.

Further research examining various work-related factors and using subjects from multiple companies should be conducted in the future.

\section{Author contributions}

M Sado drafted the protocol under supervision of J Shirahase, K Yoshimura, H Tabuchi, M Kato, and M Mimura. Y Miura and $\mathrm{K}$ Yamamoto collected data and made a dataset for analyses. M Sado and K Yoshimura conducted the analyses and wrote the first draft of the article. J Shirahase, K Yoshimura, Y Miura, K Yamamoto, H Tabuchi, M Kato, and M Mimura commented upon the manuscript and provided feedback. All authors contributed toward data analysis, drafting and revising the manuscript. All authors read and approved the final version of protocol.

\section{Disclosure}

The authors declare that they have no competing interests in this work.

\section{References}

1. Murray CJ, Vos T, Lozano R, et al. Disability-adjusted life years (DALYs) for 291 diseases and injuries in 21 regions, 1990-2010: a systematic analysis for the Global Burden of Disease Study 2010. Lancet. 2013;380(9859):2197-2223.

2. Mykletun A, Overland S, Dahl AA, et al. A population-based cohort study of the effect of common mental disorders on disability pension awards. Am J Psychiatry. 2006;163(8):1412-1418.

3. Bultmann U, Rugulies R, Lund T, Christensen KB, Labriola M, Burr H. Depressive symptoms and the risk of long-term sickness absence: a prospective study among 4747 employees in Denmark. Soc Psychiatry Psychiatr Epidemiol. 2006;41(11):875-880.

4. Bultmann U, Christensen KB, Burr H, Lund T, Rugulies R. Severe depressive symptoms as predictor of disability pension: a 10-year follow-up study in Denmark. Eur J Public Health. 2008;18(3):232-234.

5. Lerner D, Henke RM. What does research tell us about depression, job performance, and work productivity? J Occup Environ Med. 2008;50(4):401-410.

6. Eaton WW, Martins SS, Nestadt G, Bienvenu OJ, Clarke D, Alexandre P. The burden of mental disorders. Epidemiol Rev. 2008;30:1-14.

7. Shiels C, Gabbay MB, Ford FM. Patient factors associated with duration of certified sickness absence and transition to long-term incapacity. Br J Gen Pract. 2004;54(499):86-91.

8. Sado M, Inagaki A, Koreki A, et al. The cost of schizophrenia in Japan. Neuropsychiatr Dis Treat. 2013;9:787-798.

9. Sado M, Inagaki A, Yoshimura K, Koreki A, Fujisawa D. The Estimate of the Societal Cost Caused by Mental Illness (Seishin Shikkan no Shakaiteki Kosuto no Suikei). Tokyo: Ministry of Health, Labour and Welfare of Japan; 2011. Japanese.

10. Vos T, Haby MM, Barendregt JJ, Kruijshaar M, Corry J, Andrews G. The burden of major depression avoidable by longer-term treatment strategies. Arch Gen Psychiatry. 2004;61(11):1097-1103.

11. Crown WH, Neslusan C, Russo PA, Holzer S, Ozminkowski R, Croghan T. Hospitalization and total medical costs for privately insured persons with schizophrenia. Adm Policy Ment Health. 2001;28(5):335-351.

12. Maj M, Veltro F, Pirozzi R, Lobrace S, Magliano L. Pattern of recurrence of illness after recovery from an episode of major depression: a prospective study. Am J Psychiatry. 1992;149(6):795-800.

13. Mueller TI, Leon AC, Keller MB, et al. Recurrence after recovery from major depressive disorder during 15 years of observational follow-up. Am J Psychiatry. 1999;156(7):1000-1006.

14. Winokur G, Coryell W, Keller M, Endicott J, Akiskal H. A prospective follow-up of patients with bipolar and primary unipolar affective disorder. Arch Gen Psychiatry. 1993;50(6):457-465.

15. Gopinath S, Katon WJ, Russo JE, Ludman EJ. Clinical factors associated with relapse in primary care patients with chronic or recurrent depression. J Affect Disord. 2007;101(1-3):57-63.

16. Conradi HJ, de Jonge P, Ormel J. Prediction of the three-year course of recurrent depression in primary care patients: different risk factors for different outcomes. J Affect Disord. 2008;105(1-3):267-271.

17. Judd LL, Akiskal HS, Maser JD, et al. Major depressive disorder: a prospective study of residual subthreshold depressive symptoms as predictor of rapid relapse. J Affect Disord. 1998;50(2-3):97-108.

18. Pintor L, Torres X, Navarro V, Matrai S, Gasto C. Is the type of remission after a major depressive episode an important risk factor to relapses in a 4-year follow up? J Affect Disord. 2004;82(2):291-296.

19. Gonzales LR, Lewinsohn PM, Clarke GN. Longitudinal follow-up of unipolar depressives: an investigation of predictors of relapse. J Consult Clin Psychol. 1985;53(4):461-469.

20. Keller MB, Lavori PW, Lewis CE, Klerman GL. Predictors of relapse in major depressive disorder. JAMA. 1983;250(24):3299-3304.

21. Koopmans PC, Bultmann U, Roelen CA, Hoedeman R, van der Klink JJ, Groothoff JW. Recurrence of sickness absence due to common mental disorders. Int Arch Occup Environ Health. 2011;84(2):193-201.

22. Hees HL, Koeter MW, Schene AH. Predictors of long-term return to work and symptom remission in sick-listed patients with major depression. J Clin Psychiatry. 2012;73(8):e1048-e1055. 
23. Hardeveld F, Spijker J, De Graaf R, Nolen WA, Beekman AT. Prevalence and predictors of recurrence of major depressive disorder in the adult population. Acta Psychiatr Scand. 2010;122(3):184-191.

24. Crown WH, Finkelstein S, Berndt ER, et al. The impact of treatmentresistant depression on health care utilization and costs. J Clin Psychiatry. 2002;63(11):963-971.

25. Yonkers KA, Bruce SE, Dyck IR, Keller MB. Chronicity, relapse, and illness - course of panic disorder, social phobia, and generalized anxiety disorder: findings in men and women from 8 years of follow-up. Depress Anxiety. 2003;17(3):173-179.

26. Robinson OJ, Sahakian BJ. Recurrence in major depressive disorder: a neurocognitive perspective. Psychol Med. 2008;38(3):315-318.

27. Burcusa SL, Iacono WG. Risk for recurrence in depression. Clin Psychol Rev. 2007;27(8):959-985.

28. Judd LL, Paulus MJ, Schettler PJ, et al. Does incomplete recovery from first lifetime major depressive episode herald a chronic course of illness? Am J Psychiatry. 2000;157(9):1501-1504.

29. Paykel ES, Ramana R, Cooper Z, Hayhurst H, Kerr J, Barocka A. Residual symptoms after partial remission: an important outcome in depression. Psychol Med. 1995;25(6):1171-1180.

30. Pintor L, Gasto C, Navarro V, Torres X, Fananas L. Relapse of major depression after complete and partial remission during a 2-year followup. J Affect Disord. 2003;73(3):237-244.
31. Bijl RV, De Graaf R, Ravelli A, Smit F, Vollebergh WA. Gender and age-specific first incidence of DSM-III-R psychiatric disorders in the general population. Results from The Netherlands Mental Health Survey and Incidence Study (NEMESIS). Soc Psychiatry Psychiatr Epidemiol. 2002;37(8):372-379.

32. Spijker J, de Graaf R, Bijl RV, Beekman AT, Ormel J, Nolen WA. Duration of major depressive episodes in the general population: results from The Netherlands Mental Health Survey and Incidence Study (NEMESIS). Br J Psychiatry. 2002;181:208-213.

33. Koopmans PC, Roelen CA, Groothoff JW. Frequent and long-term absence as a risk factor for work disability and job termination among employees in the private sector. Occup Environ Med. 2008;65(7): 494-499.

34. Anthony JC, Petronis KR. Suspected risk factors for depression among adults 18-44 years old. Epidemiology. 1991;2(2):123-132.

35. De Graaf R, Bijl RV, Ravelli A, Smit F, Vollebergh WA. Predictors of first incidence of DSM-III-R psychiatric disorders in the general population: findings from The Netherlands Mental Health Survey and Incidence Study. Acta Psychiatr Scand. 2002;106(4):303-313.

36. Hensing G, Wahlstrom R. Swedish Council on Technology Assessment in Health Care (SBU). Chapter 7. Sickness absence and psychiatric disorders. Scand J Public Health Suppl. 2004;63:152-180.
Neuropsychiatric Disease and Treatment

\section{Publish your work in this journal}

Neuropsychiatric Disease and Treatment is an international, peerreviewed journal of clinical therapeutics and pharmacology focusing on concise rapid reporting of clinical or pre-clinical studies on a range of neuropsychiatric and neurological disorders. This journal is indexed on PubMed Central, the 'PsycINFO' database and CAS.

\section{Dovepress}

The manuscript management system is completely online and includes a very quick and fair peer-review system, which is all easy to use. Visit http://www.dovepress.com/testimonials.php to read real quotes from published authors. 